\title{
Specific Binding Sites for an Antifungal Plant Defensin from Dahlia (Dahlia merckii) on Fungal Cells Are Required for Antifungal Activity
}

\author{
Karin Thevissen, ${ }^{1}$ Rupert W. Osborn, ${ }^{2}$ David P. Acland, ${ }^{2}$ and Willem F. Broekaert ${ }^{1}$ \\ ${ }^{1}$ F. A. Janssens Laboratory of Genetics, Katholieke Universiteit Leuven, K. Mercierlaan 92, B-3001 \\ Heverlee-Leuven, Belgium; 'Zeneca Agrochemicals, Jealott's Hill Research Station, Bracknell, \\ Berkshire, RG42 6ET, U.K. \\ Accepted 13 September 1999.
}

\begin{abstract}
Dm-AMP1, an antifungal plant defensin from seeds of dahlia (Dahlia merckii), was radioactively labeled with tbutoxycarbonyl-[ $\left.{ }^{35} \mathrm{~S}\right]-\mathrm{L}$-methionine $N$-hydroxy-succinimidylester. This procedure yielded a ${ }^{35} \mathrm{~S}$-labeled peptide with unaltered antifungal activity. $\left[{ }^{35} \mathrm{~S}\right] \mathrm{Dm}-\mathrm{AMP1}$ was used to assess binding on living cells of the filamentous fungus Neurospora crassa and the unicellular fungus Saccharomyces cerevisiae. Binding of $\left[{ }^{35} \mathrm{~S}\right] \mathrm{Dm}-\mathrm{AMP} 1$ to fungal cells was saturable and could be competed for by preincubation with excess, unlabeled Dm-AMP1 as well as with AhAMP1 and Ct-AMP1, two plant defensins that are highly homologous to Dm-AMP1. In contrast, binding could not be competed for by more distantly related plant defensins or structurally unrelated antimicrobial peptides. Binding of $\left[{ }^{35} \mathrm{~S}\right] \mathrm{Dm}$-AMP1 to either $N$. crassa or $S$. cerevisiae cells was apparently irreversible. In addition, whole cells and microsomal membrane fractions from two independently obtained $S$. cerevisiae mutants selected for resistance to Dm-AMP1 exhibited severely reduced binding affinity for $\left[{ }^{35} \mathrm{~S}\right] \mathrm{Dm}-\mathrm{AMP1}$, compared with wild-type yeast. This finding suggests that binding of Dm-AMP1 to $S$. cerevisiae plasma membranes is required for antifungal activity of this protein.
\end{abstract}

Plants protect themselves against microbial pathogens by various defense responses such as the modification of plant cell walls and the production of antimicrobial, secondary metabolites (phytoalexins), lytic enzymes such as chitinases and glucanases, and membrane-interacting proteins and peptides (reviewed by Kombrink and Somssich 1995). One particular family of antimicrobial peptides that inhibit growth of a broad range of fungi at micromolar concentrations are the plant defensins (reviewed by Broekaert et al. 1995, 1997). Plant defensins are small (45 to 54 amino acids), basic peptides that share a common, characteristic, three-dimensional folding pattern, stabilized by eight disulfide-linked cysteines. Plant defensins are structurally related to insect defensins

Corresponding author: Willem F. Broekaert, Katholieke Universiteit Leuven, K. Mercierlaan 92, B-3001 Heverlee-Leuven;

Telephone: +32-16-321631; Fax: +32-16-321966

E-mail: willem.broekaert@agr.kuleuven.ac.be
(Broekaert et al. 1995) and even more to the antifungal insect peptide drosomycin (Landon et al. 1997). Based on amino acid sequence homologies, plant defensins can be divided into two main groups (A and B) sharing only $25 \%$ similarity (Harrison et al. 1997). In group A, four subfamilies can be distinguished (A1, A2, A3, and A4) with at least 50\% similarity within each subfamily. Subfamily A2 contains plant defensins such as Dm-AMP1 from Dahlia merckii, Ah-AMP1 from Aesculus hippocastanum, and Ct-AMP1 from Clitoria ternatea, which share about $70 \%$ sequence identity with each other. These plant defensins also have a similar antimicrobial activity spectrum and susceptible fungi show reduced hyphal elongation without marked morphological distortions (Osborn et al. 1995). They have, therefore, been said to be 'nonmorphogenic' in their inhibitory effect on fungi (Broekaert et al. 1995). Subfamily A3 consists of plant defensins from Brassicaceae, including Rs-AFP2 from Raphanus sativus. Subfamily A4 so far only contains Hs-AFP1 from Heuchera sanguinea. Members of subfamilies A3 and A4 inhibit fungi in a different way than do members of subfamily A2, as they induce tip ballooning and branch formation on susceptible fungi (Osborn et al. 1995). These plant defensins have therefore been termed 'morphogenic' plant defensins (Broekaert et al. 1995).

Treatment of hyphae of Neurospora crassa with either of the antifungal plant defensins Rs-AFP2 (subfamily A3) or Dm-AMP1 (subfamily A2) induces an array of relatively rapid membrane responses, including $\mathrm{K}^{+}$efflux, $\mathrm{Ca}^{2+}$ uptake, alkalinization of the incubation medium, and membrane potential changes (Thevissen et al. 1996). In contrast to insect defensins (Cociancich et al. 1993) and mammalian defensins (Kagan et al. 1990), plant defensins do not form ion-permeable pores in artificial membranes (Thevissen et al. 1996). Furthermore, the existence of specific, high affinity binding sites for the morphogenic plant defensin Hs-AFP1 (subfamily A4) on $N$. crassa hyphae and microsomal membranes was demonstrated (Thevissen et al. 1997). Binding of Hs-AFP1 to these sites was saturable with an apparent $\mathrm{K}_{\mathrm{d}}$ of about $30 \mathrm{nM}$ and was partially reversible. In addition, indirect evidence has been obtained suggesting that binding of Hs-AFP1 to this binding site is linked to its antifungal effects. For instance, a single amino acid substitution variant of Rs-AFP2 that lacked antifungal activity (De Samblanx et al. 1997) was unable to compete for this plant defensin binding site, unlike Rs-AFP2 itself 
(Thevissen et al. 1997). In conclusion, it seems likely that binding of Hs-AFP1 with a fungal plasma membrane binding site is the first step in the path leading to fungal growth inhibition.

In this study, we have assessed the presence of specific binding sites for Dm-AMP1, a member of the abovementioned subfamily A2 of nonmorphogenic plant defensins, on the filamentous fungus $N$. crassa and the unicellular fungus Saccharomyces cerevisiae. To this end, we have used a ${ }^{35} \mathrm{~S}$ labeled derivative of Dm-AMP1. Our results point to the presence of highly specific binding sites for Dm-AMP1 on fungal cells. Binding of Dm-AMP1 to fungal cells appears to be required for antifungal activity, as yeast mutants selected for resistance to Dm-AMP1 showed drastically reduced binding activity.

\section{RESULTS}

\section{Antifungal activity of Dm-AMP1}

and its nonradioactive derivative.

Boc- $\left[{ }^{35} \mathrm{~S}\right] \mathrm{Met}-\mathrm{NHS}$ was used to produce a radiolabeled derivative of Dm-AMP1, a nonmorphogenic plant defensin of subfamily A2 from Dahlia merckii seed. To test the effect of the derivatization reaction on the antifungal activity of DmAMP1, the peptide was allowed to react with nonradioactive Boc-Met-NHS and the specific antifungal activity of the modified peptide was assayed in an antifungal activity assay against four fungal species with different sensitivities to DmAMP1. The antifungal activity of modified and unmodified Dm-AMP1 was essentially the same for the four fungi (Table 1). Therefore, it was concluded that the labeling reaction was unlikely to greatly affect binding of modified Dm-AMP1 to its target.

\section{Saturability of binding of $\left[{ }^{35} \mathrm{~S}\right] \mathrm{Dm}-\mathrm{AMP1}$ to fungi.}

$\left[{ }^{35} \mathrm{~S}\right] \mathrm{Dm}-\mathrm{AMP} 1$ was found to bind both to hyphae of the filamentous fungus $N$. crassa and to cells of the yeast $S$. cerevisiae. Saturability of the binding of Dm-AMP1 to N. crassa hyphae and $S$. cerevisiae cells was examined by incubation with increasing concentrations of $\left[{ }^{35} \mathrm{~S}\right] \mathrm{Dm}$-AMP1 (2 to 2,000

Table 1. Antifungal activity of Dm-AMP1, Ah-AMP1, Ct-AMP1, and Dm-AMP1 modified with Boc-Met-NHS (Boc-Met-HsAFP1) on different fungi

\begin{tabular}{|c|c|c|c|c|}
\hline \multirow[b]{2}{*}{ Fungus } & \multicolumn{4}{|c|}{$\mathrm{IC}_{50}(\mu \mathrm{M})^{\mathrm{a}}$} \\
\hline & $\begin{array}{l}\text { Dm- } \\
\text { AMP1 }\end{array}$ & $\begin{array}{l}\text { Boc- } \\
\text { Met- } \\
\text { Dm- } \\
\text { AMP1 }\end{array}$ & $\begin{array}{l}\text { Ah- } \\
\text { AMP1 }\end{array}$ & Ct-AMP1 \\
\hline Neurospora crassa & $2.2 \pm 0.8$ & $3.1 \pm 0.9$ & $\mathrm{ND}^{\mathrm{b}}$ & ND \\
\hline Alternaria brassicicola & $2.4 \pm 0.5$ & $2.0 \pm 0.7$ & ND & ND \\
\hline Botrytis cinerea & $>80.0$ & $>80.0$ & ND & ND \\
\hline Fusarium culmorum & $8.0 \pm 3.0$ & $9.0 \pm 5.0$ & ND & ND \\
\hline $\begin{array}{l}\text { Saccharomyces cere- } \\
\text { visiae (WT) }\end{array}$ & $2.0 \pm 0.3$ & ND & $2.3 \pm 0.3$ & $2.1 \pm 0.2$ \\
\hline S. cerevisiae (DM1) & $>40.0$ & ND & $>40.0$ & $>40.0$ \\
\hline S. cerevisiae (DM2) & $>40.0$ & ND & $>40.0$ & $>40.0$ \\
\hline
\end{tabular}

$\mathrm{nM})$. As can be seen in Figure $1 \mathrm{~A}$ and B, saturation curves obtained with either $N$. crassa hyphae or $S$. cerevisiae cells were hyperbolic. Half-maximal binding of $\left[{ }^{35} \mathrm{~S}\right] \mathrm{Dm}-\mathrm{AMP} 1$ to $N$. crassa hyphae occurred at $60 \mathrm{nM}$, whereas half-maximal binding of $\left[{ }^{35} \mathrm{~S}\right] \mathrm{Dm}-\mathrm{AMP} 1$ to $S$. cerevisiae cells occurred at 250 to $300 \mathrm{nM}$. Since binding of $\left[{ }^{35} \mathrm{~S}\right] \mathrm{Dm}-\mathrm{AMP} 1$ to fungal cells seems to be irreversible (see below), Scatchard analysis of the specific binding data was not performed.

\section{Reversibility of binding of $\left[{ }^{35} \mathrm{~S}\right] \mathrm{Dm}-\mathrm{AMP} 1$ to fungi.}

Association kinetics of binding of Dm-AMP1 to N. crassa hyphae and $S$. cerevisiae cells was determined by incubation of $\left[{ }^{35} \mathrm{~S}\right] \mathrm{Dm}$-AMP1 for increasing periods of time. Dissociation was initiated after $30 \mathrm{~min}$ of incubation by addition of an excess of unlabeled Dm-AMP1. Incubation of $\left[{ }^{35} \mathrm{~S}\right] \mathrm{Dm}-\mathrm{AMP} 1$

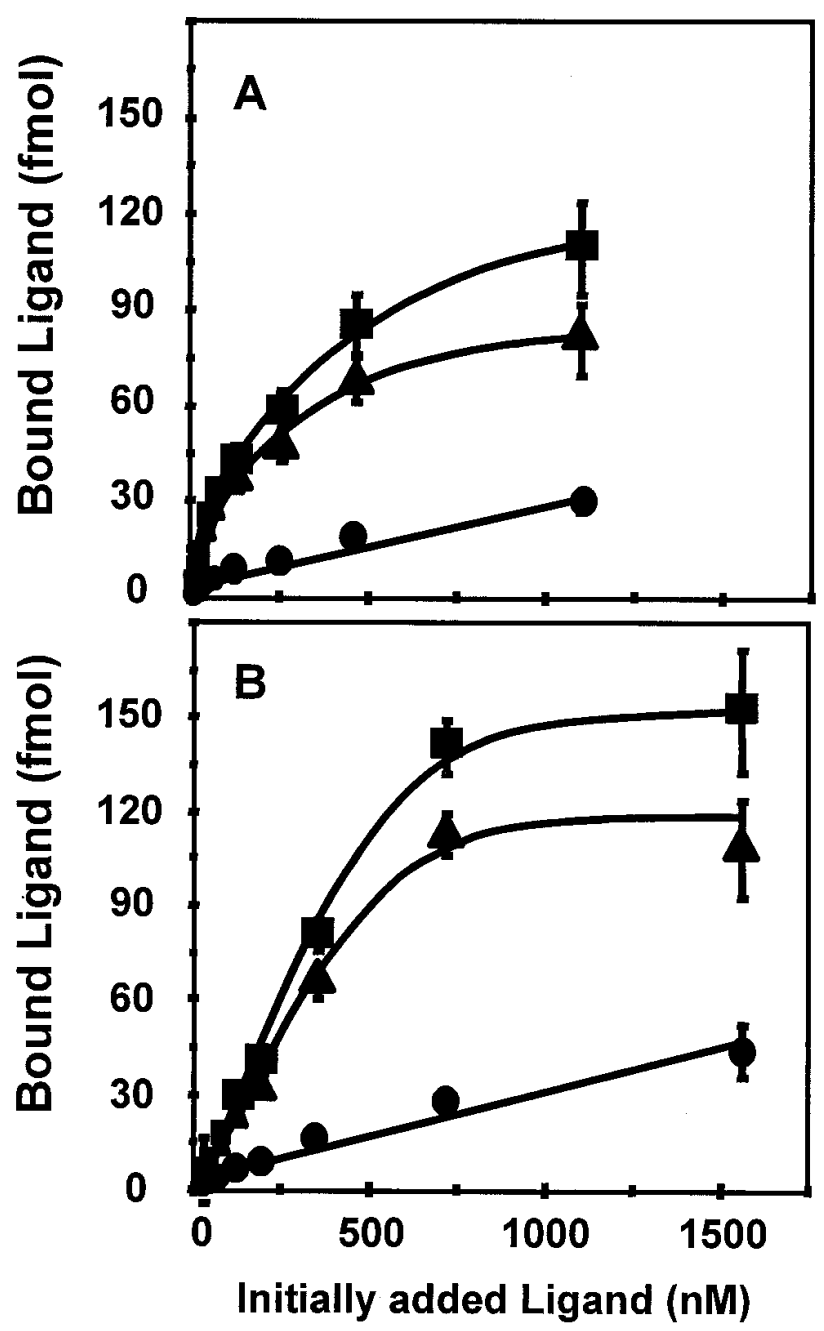

Fig. 1. Saturability of binding of $\left[{ }^{35} \mathrm{~S}\right] \mathrm{Dm}-\mathrm{AMP} 1$ to Neurospora crassa hyphae and Saccharomyces cerevisiae cells. Increasing amounts of $\left.{ }^{35} \mathrm{~S}\right] \mathrm{Dm}$-AMP1, diluted with unlabeled Dm-AMP1 to a final specific radioactivity of $0.015 \mathrm{TBq} / \mathrm{mmol}$, were added to either (A) $N$. crassa hyphae or (B) S. cerevisiae cells in the absence (squares, total binding) or presence of $25 \mu \mathrm{M}$ unlabeled Dm-AMP1 (circles, nonspecific binding). Specific binding (triangles) was determined as the difference between total binding and nonspecific binding. Data correspond to one representative experiment out of three. Data are expressed as means \pm standard error of three independent determinations. 
with $N$. crassa hyphae resulted in rapid binding of the radioligand; half-maximal binding occurred within 5 min (Fig. 2A). Dissociation of radiolabeled Dm-AMP1 from its binding sites on hyphae in the presence of excess, unlabeled Dm-AMP1 was not observed even after $2 \mathrm{~h}$, indicating either that $\left[{ }^{35} \mathrm{~S}\right] \mathrm{Dm}$-AMP1 binding to hyphae is irreversible or that dissociation is very slow. Nonspecific binding, determined by addition of $50 \mu \mathrm{M}$ unlabeled Dm-AMP1, remained at about 15 to $20 \%$ of total binding throughout the experiment.

To confirm the apparent irreversible nature of Dm-AMP1 binding, the following experiment was set up. Two identical sets of $N$. crassa hyphae were allowed to bind $\left[{ }^{35} \mathrm{~S}\right] \mathrm{Dm}-\mathrm{AMP} 1$ for $1 \mathrm{~h}$, whereafter a ninefold excess of binding buffer

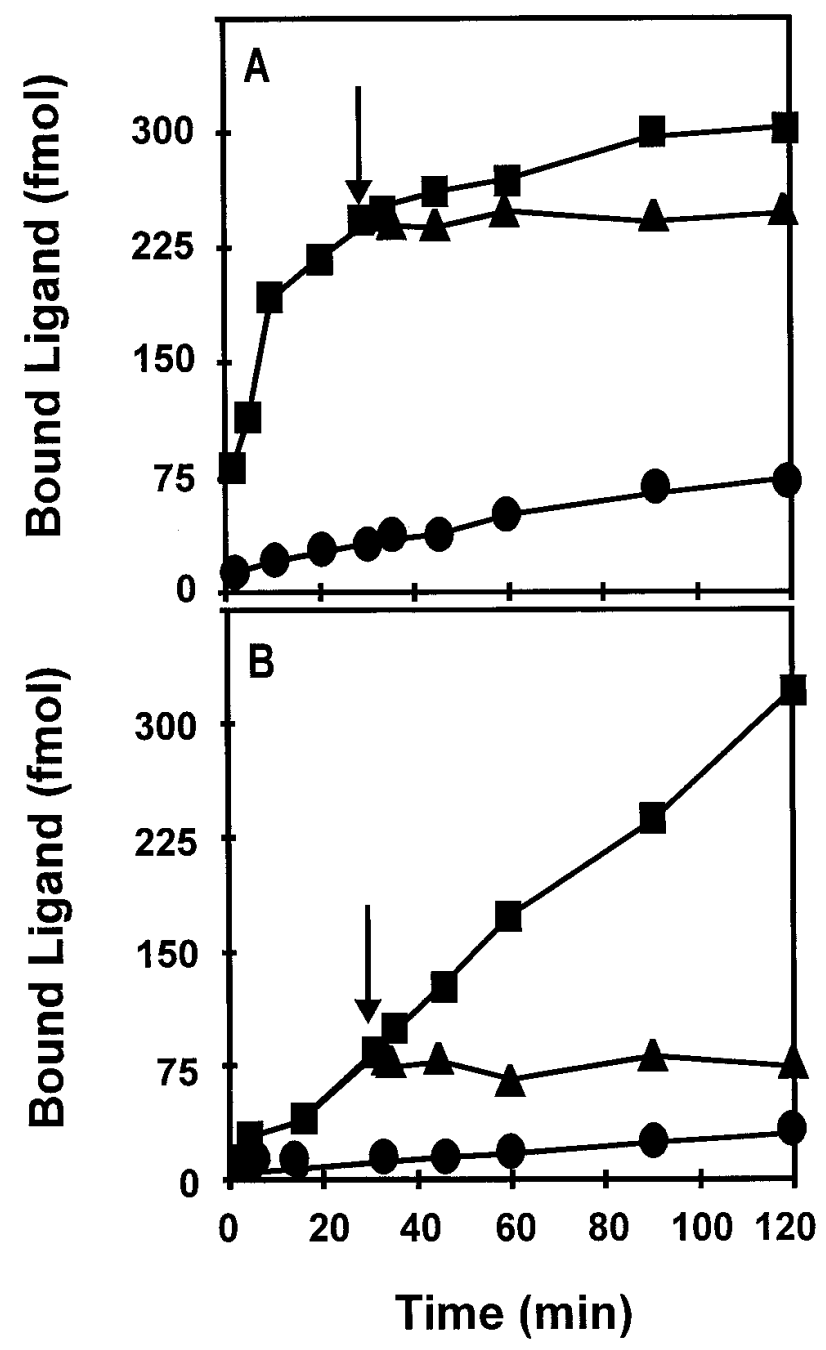

Fig. 2. Kinetics of binding and dissociation of $\left[{ }^{35} \mathrm{~S}\right] \mathrm{Dm}-\mathrm{AMP} 1$ to $\mathrm{Neu}$ rospora crassa hyphae and Saccharomyces. cerevisiae cells. Association kinetics for Dm-AMP1 ( $\mathbf{\square})$ binding to (A) $N$. crassa hyphae and (B) $S$. cerevisiae cells were determined by addition of $\left[{ }^{35}\right.$ S]Dm-AMP1 (40 nM) at time 0 and incubation of samples for increasing time intervals. Dissociation kinetics of Dm-AMP1 binding $(\boldsymbol{\Delta})$ were initiated $30 \mathrm{~min}$ after addition of $\left[{ }^{35} \mathrm{~S}\right] \mathrm{Dm}-\mathrm{AMP} 1$ by addition of $50 \mu \mathrm{M}$ unlabeled Dm-AMP1 (arrow). Nonspecific binding of $\left[{ }^{35} \mathrm{~S}\right] \mathrm{Dm}$-AMP1 (•) was measured by addition of $50 \mu \mathrm{M}$ unlabeled Dm-AMP1, simultaneously with $\left[{ }^{35} \mathrm{~S}\right] \mathrm{Dm}$ AMP1 at time 0. Data are averages of duplicate measurements and correspond to one representative experiment out of three. (lacking Dm-AMP1) was added to one set of $N$. crassa hyphae. After another $2 \mathrm{~h}$ of incubation, binding of $\left[{ }^{35} \mathrm{~S}\right] \mathrm{Dm}-$ AMP1 to both sets was compared and found not to differ significantly (results not shown). This indicates that 10 -fold dilution of free $\left[{ }^{35} \mathrm{~S}\right] \mathrm{Dm}$-AMP1 had not entailed the establishment of a new binding equilibrium.

Very similar results were obtained when $S$. cerevisiae cells were used instead of $N$. crassa hyphae. As can be seen in Figure $2 \mathrm{~B}$, association of $\left[{ }^{35} \mathrm{~S}\right] \mathrm{Dm}-\mathrm{AMP} 1$ to its binding sites on $S$. cerevisiae cells did not reach a saturation level after $2 \mathrm{~h}$ of incubation. Dissociation of radiolabeled Dm-AMP1 from its binding sites on yeast cells in the presence of a 1,250-fold excess of unlabeled Dm-AMP1 was not observed even after $2 \mathrm{~h}$, indicating that $\left[{ }^{35} \mathrm{~S}\right] \mathrm{Dm}$-AMP1 binding to $S$. cerevisiae cells is irreversible. Nonspecific binding, determined by addition of $50 \mu \mathrm{M}$ unlabeled Dm-AMP1, remained at about 10 to $15 \%$ of total binding throughout the experiment.

Specificity of binding of ${ }^{35} \mathrm{~S}$-labeled Dm-AMP1 to fungi.

To investigate whether binding of Dm-AMP1 to fungi was competitive, $N$. crassa hyphae or $S$. cerevisiae cells were preincubated with increasing concentrations of native, unlabeled Dm-AMP1 for 15 min prior to addition of radiolabeled Dm-AMP1. Binding of $\left[{ }^{35} \mathrm{~S}\right] \mathrm{Dm}-\mathrm{AMP} 1$ on both $N$. crassa hyphae and $S$. cerevisiae cells could efficiently be competed for by preincubation with excess, unlabeled Dm-AMP1. Concentrations of unlabeled Dm-AMP1 required for 50\% inhibition of binding were about 0.4 and $3 \mu \mathrm{M}$ for $N$. crassa and $S$. cerevisiae, respectively (Fig. 3A, B).

In order to further assess the specificity of binding of ${ }^{35} \mathrm{~S}$ labeled Dm-AMP1, the ability of different antifungal peptides to compete with $\left[{ }^{35} \mathrm{~S}\right] \mathrm{Dm}$-AMP1 was tested, both on $N$. crassa hyphae and $S$. cerevisiae cells. The antifungal peptides used in this experiment were Ah-AMP1 and Ct-AMP1, plant defensins isolated from seed of horse chestnut (Aesculus hippocastanum) and Clitoria ternatea, respectively, that show 68 and $72 \%$ sequence identity to Dm-AMP1, respectively (Osborn et al. 1995); Rs-AFP2, isolated from seed of radish (Raphanus sativus) (Terras et al. 1992) and Hs-AFP1, isolated from seed of Heuchera sanguinea (Osborn et al. 1995), which are plant defensins with 50 and $46 \%$ sequence identity to Dm-AMP1, respectively; Ace-AMP1, isolated from onion (Allium cepa) seed and structurally related to lipid transfer proteins (Cammue et al. 1995); Ac-AMP1, isolated from amaranth (Amaranthus caudatus) seed and belonging to the hevein-type antimicrobial peptides (Broekaert et al. 1992, 1997); Mj-AMP1, isolated from Mirabilis jalapa seed and belonging to the knottin-type antimicrobial peptides (Cammue et al. 1992; Broekaert et al. 1997); and Ib-AMP4, a 20 amino acid antimicrobial peptide with two disulfide bridges isolated from Impatiens balsamina seed (Tailor et al. 1997). [ ${ }^{35}$ S]Dm-AMP1 binding to either $N$. crassa hyphae or $S$. cerevisiae cells could only be competed for by members of the A2 subfamily of plant defensins (Dm-AMP1, Ah-AMP1, and Ct-AMP1) but not by the plant defensins belonging to subfamilies A3 and A4 (Rs-AFP2 and Hs-AFP1, respectively) nor by the structurally unrelated antimicrobial peptides (Ace-AMP1, Ac-AMP1, MjAMP1, and Ib-AMP4) (Fig. 4A, B).

It has previously been shown that plant defensins lose their antifungal activity upon reduction of their disulfide bridges (Terras et al. 1992) as well as upon addition of divalent 
cations to the growth medium (Terras et al. 1993; Osborn et al. 1995; Thevissen et al. 1996). Reduced Dm-AFP1 at $40 \mu \mathrm{M}$ was unable to compete with binding of $\left[{ }^{35} \mathrm{~S}\right] \mathrm{Dm}$-AFP1 to $N$. crassa hyphae. Addition of $20 \mathrm{mM} \mathrm{MgCl} 2$ to the binding assay reduced binding of $\left[{ }^{35} \mathrm{~S}\right] \mathrm{Dm}-\mathrm{AFP} 1$ to $N$. crassa hyphae by over $93 \%$ (results not shown).

\section{Isolation and characterization of $S$. cerevisiae mutants resistant to Dm-AMP1.}

By a selection procedure performed in liquid medium containing $5 \mu \mathrm{M}$ Dm-AMP1, two independent Dm-AMP1resistant $S$. cerevisiae colonies could be isolated (DM1 and DM2). The antifungal activity of Dm-AMP1 on wild-type $S$. cerevisiae and on the yeast mutants resistant to Dm-AMP1 was assessed (Table 1). Wild-type yeast was found to be sensitive to Dm-AMP1 at concentrations above 1 to $2 \mu \mathrm{M}$,

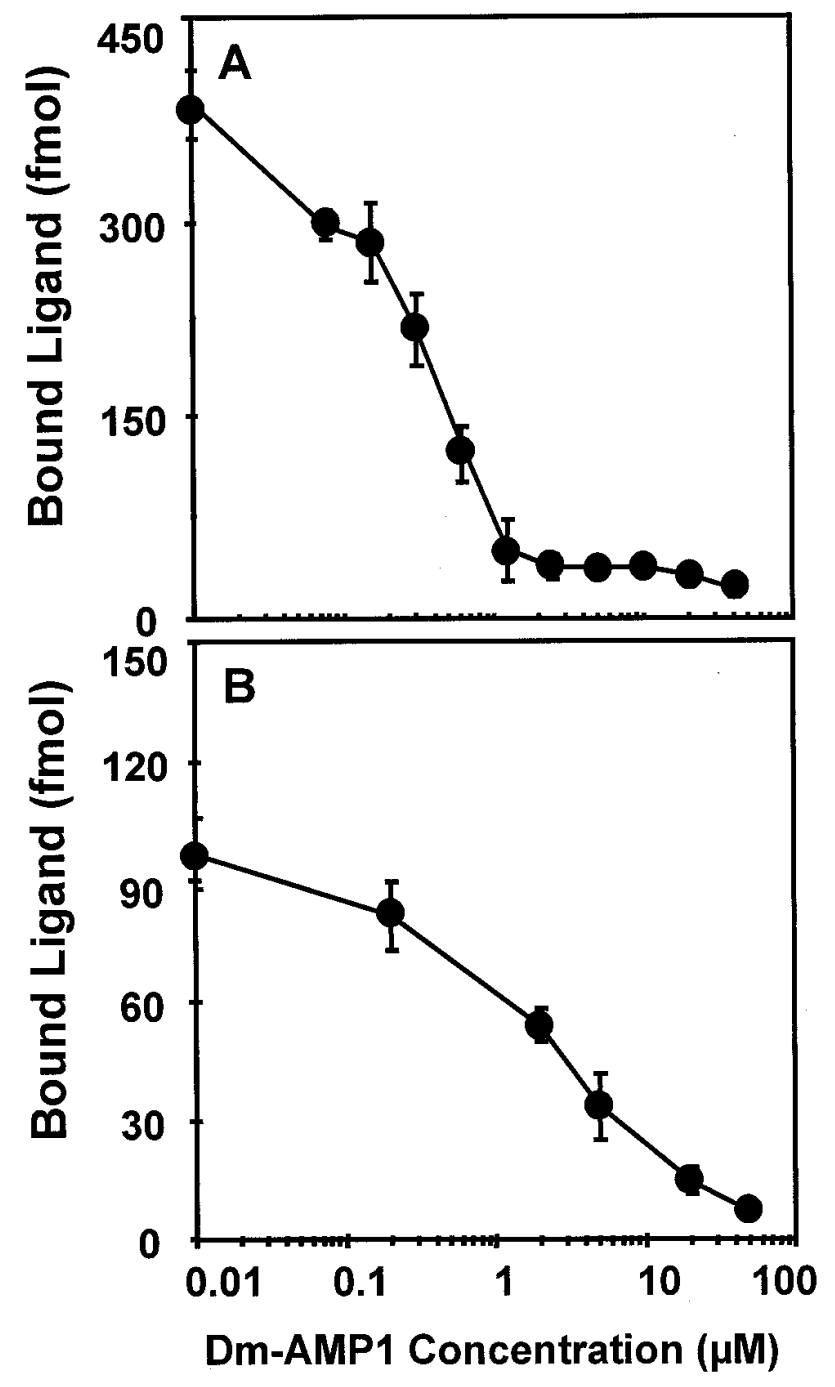

Fig. 3. Competitivity of binding of $\left[{ }^{35} \mathrm{~S}\right] \mathrm{Dm}$-AMP1 to Neurospora crassa hyphae and Saccharomyces cerevisiae cells. Binding of $\left[{ }^{35} \mathrm{~S}\right] \mathrm{Dm}-$ AMP1 (40 nM) to (A) N. crassa hyphae and (B) S. cerevisiae cells in the presence of increasing amounts of unlabeled Dm-AMP1 is shown. Unlabeled Dm-AMP1 was added 15 min prior to addition of $\left[{ }^{35} \mathrm{~S}\right] \mathrm{Dm}-$ AMP1. Reaction volume of the assay was $100 \mu$ l. Data are means \pm standard error of three independent determinations. whereas the Dm-AMP1-resistant yeast mutants were resistant up to $40 \mu \mathrm{M}$ Dm-AMP1. In addition, the resistant mutants showed comparable resistance levels to Ah-AMP1 and CtAMP1 (Table 1), two nonmorphogenic plant defensins belonging, as does Dm-AMP1, to subfamily A2.

The Dm-AMP1-resistant yeast mutants might have acquired resistance to Dm-AMP1 due to overproduction of Dm-AMP1degrading proteases. In order to assess this possibility, wildtype yeast and the Dm-AMP1-resistant yeast mutants (DM1 and DM2) were incubated with Dm-AMP1 for $24 \mathrm{~h}$ at $30^{\circ} \mathrm{C}$. After this incubation, the antifungal activity of the supernatants containing Dm-AMP1 were assessed against the test fungus $N$. crassa. No substantial differences in antifungal activity were observed, indicating that the resistant yeast strains did not preferentially degrade Dm-AMP1 (results not shown). We also tested the susceptibility of DM1, DM2, and wild-type

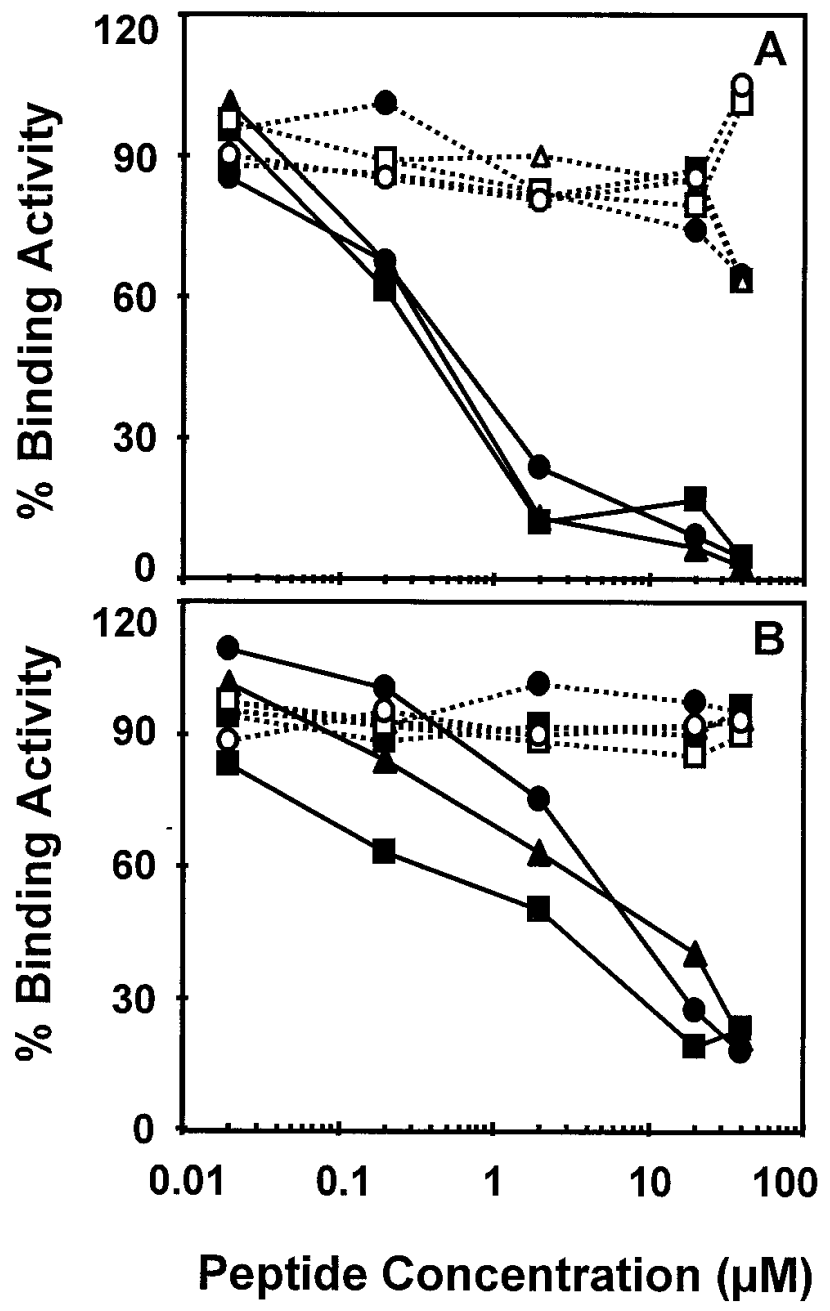

Fig. 4. Inhibition of binding of $\left[{ }^{35} \mathrm{~S}\right] \mathrm{Dm}-\mathrm{AMP} 1$ to Neurospora crassa hyphae and Saccharomyces cerevisiae cells by different antifungal peptides. $\left[{ }^{35}\right.$ S]Dm-AMP1 $(40 \mathrm{nM})$ was incubated with (A) N. crassa hyphae and (B) S. cerevisiae cells, together with increasing amounts of DmAMP1 (- -), Ah-AMP1 (- -$)$, Ct-AMP1 (- -$)$, Rs-AFP2 $(\bullet \bullet \bullet \bullet)$, Hs-AFP1 $(\bullet \bullet \bullet \bullet \bullet)$, Ac-AMP1 $(\bullet \bullet \Delta \bullet \bullet), \operatorname{Mj}-\operatorname{AMP} 2(\bullet \bullet \square \bullet \bullet)$ and Ib-AMP4 $(\bullet \bullet \bullet \bullet \bullet)$. Unlabeled proteins were added $15 \mathrm{~min}$ prior to addition of $\left[{ }^{35} \mathrm{~S}\right] \mathrm{Dm}-\mathrm{AMP} 1$. Data are averages of triplicate measurements and correspond to one representative experiment out of three. 
yeast to three different antifungal drugs (verapamil, carbonylcyanide m-chlorophenylhydrazone, and carbendazim), but found no difference between the mutants and wild-type yeast (results not shown).

\section{Binding of $\left[{ }^{35} \mathrm{~S}\right] \mathrm{Dm}-\mathrm{AMP} 1$ to resistant $S$. cerevisiae mutants.}

In order to investigate whether the Dm-AMP1-resistant mutants would be affected in their binding capacity for DmAMP1, binding assays with $\left[{ }^{35} \mathrm{~S}\right] \mathrm{Dm}$-AMP1 were performed on the mutants DM1 and DM2 and wild-type yeast strain. In these comparative binding assays, the Dm-AMP1-resistant mutants were both found to bind about 10 -fold less $\left[{ }^{35} \mathrm{~S}\right] \mathrm{Dm}$ AMP1 than wild-type yeast cells (Fig. 5A). Binding of $\left[{ }^{35} \mathrm{~S}\right] \mathrm{Dm}-\mathrm{AMP} 1$ to DM1 and DM2 was about as high as binding to yeast cells preincubated with an excess of $50 \mu \mathrm{M}$ unlabeled Dm-AMP1, indicating that most of the residual binding to DM1 and DM2 results from nonspecific binding.

To exclude the possibility that reduced Dm-AMP1 binding by the Dm-AMP1-resistant mutants was due to alterations in their cell wall composition or structure, $\left[{ }^{35} \mathrm{~S}\right] \mathrm{Dm}$-AMP1 binding to plasma membrane fractions derived from wild-type and Dm-AMP1-resistant yeast mutants was assessed. As can be seen in Figure 5B, the binding capacity of wild-type plasma membranes for $\left[{ }^{35} \mathrm{~S}\right] \mathrm{Dm}$-AMP1 was about sevenfold higher, compared with that of plasma membranes derived from the resistant mutants.

\section{DISCUSSION}

In the present study, we have examined the binding of DmAMP1, a member of the A2 subfamily of plant defensins, to living $N$. crassa and $S$. cerevisiae cells. To this end, DmAMP1 was subjected to a labeling procedure consisting of the derivatization of primary amino groups with Boc-Met-NHS. The resulting modified peptide had essentially the same antifungal activity against four fungal species tested, indicating that the modifications had not affected side chains that are important for interaction with the fungal target.

Binding of radiolabeled Dm-AMP1 to $N$. crassa hyphae and $S$. cerevisiae cells appeared to be specific and saturable, and could be competed for by preincubation with excess unlabeled Dm-AMP1. However, no competition for binding sites occurred when the excess, unlabeled Dm-AMP1 was added 30 min after the labeled peptide, indicating that the binding is irreversible. This is in contrast to binding of Hs-AFP1 to N. crassa hyphae, which was shown to be at least partially reversible (Thevissen et al. 1997). Binding of radiolabeled Dm-AMP1 (subfamily A2) could also be competed for by preincubation with the subfamily A2 plant defensins Ah-AMP1 and Ct-AMP1, but not by subfamily A3 or A4 plant defensins. In contrast, binding of Hs-AFP1 (subfamily A4) could only be efficiently competed for by itself and to a much lesser extent by the subfamily A2 and A3 plant defensins (Thevissen et al. 1997). None of the structurally unrelated peptides tested showed any significant competition for the binding sites of Dm-AMP1 (Fig. 4) or HsAFP1 (Thevissen et al. 1997). These results indicate that the binding sites for plant defensins are highly specific and, furthermore, that the binding sites for subfamily A2 plant defensins and subfamily A4 plant defensins in N. crassa are distinct. They might, however, be structurally related.
Due to the irreversible nature of Dm-AMP1 binding to fungal cells, it was not possible to determine a dissociation constant. The apparently irreversible binding of $\left[{ }^{35} \mathrm{~S}\right] \mathrm{Dm}-$ AMP1 to fungal cells could be the result of a low rate constant for dissociation. If this is the case, then the dissociation half-time for binding of $\left[{ }^{35} \mathrm{~S}\right] \mathrm{Dm}$-AMP1 to $N$. crassa hyphae has to be higher than $120 \mathrm{~min}$, as can be concluded from the experimental data in Figure 2A. Alternatively, irreversibility could be due to binding site-mediated insertion of $\left[{ }^{35} \mathrm{~S}\right] \mathrm{Dm}-\mathrm{AMP} 1$ into the plasma membrane. In this case, the

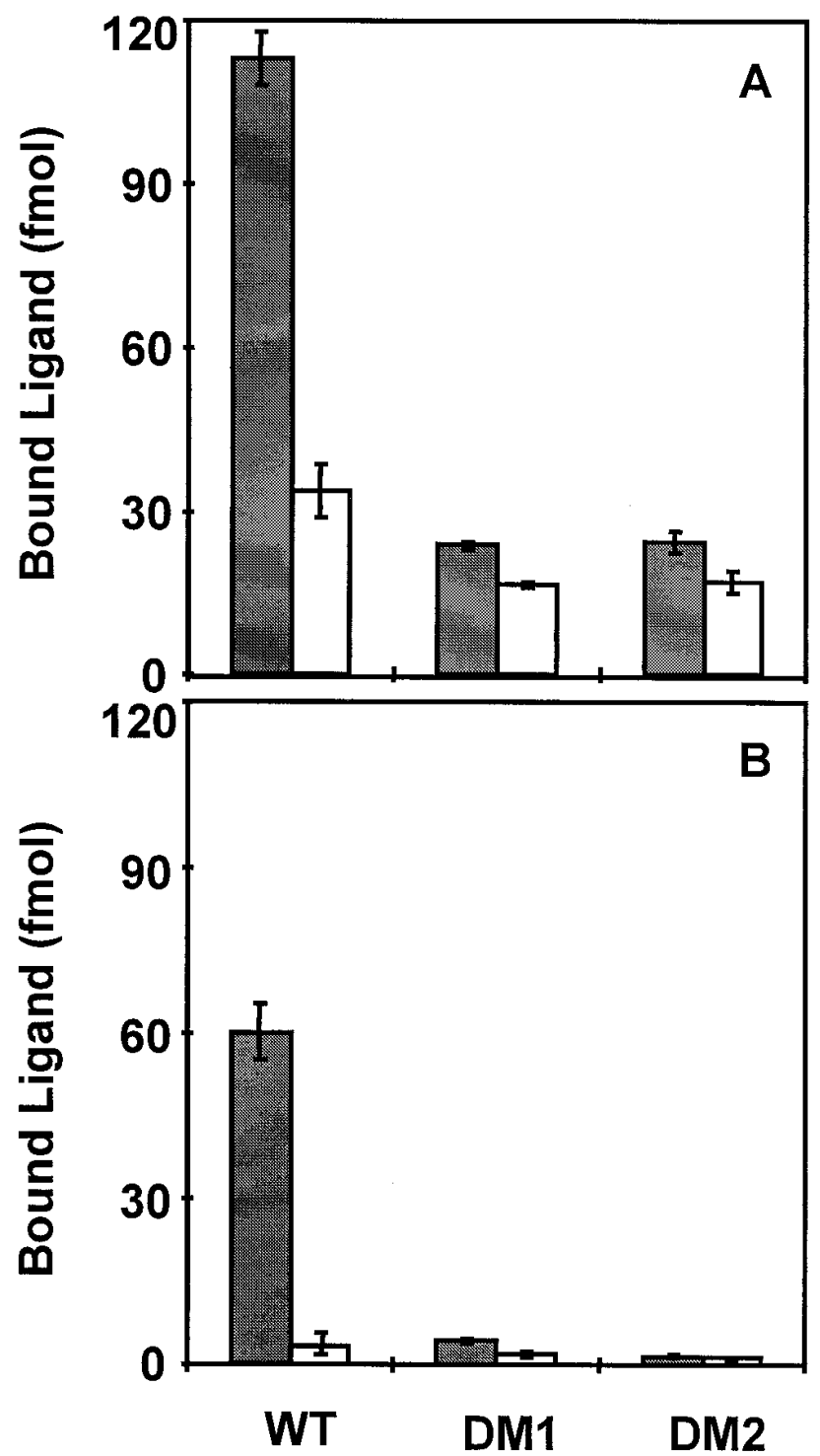

Fig. 5. $\left[{ }^{35} \mathrm{~S}\right] \mathrm{Dm}$-AMP1 binding capacity of wild-type yeast and DmAMP1-resistant yeast mutants. A, $\left.{ }^{35} \mathrm{~S}\right] \mathrm{Dm}-\mathrm{AMP} 1(40 \mathrm{nM})$ was incubated with wild-type yeast cells or Dm-AMP1-resistant mutant yeast cells DM1 or DM2. B, $\left.{ }^{35} \mathrm{~S}\right] \mathrm{Dm}-\mathrm{AMP} 1(240 \mathrm{nM})$ was incubated with plasma membrane fractions derived from wild-type or mutant DM1 or DM2 yeast cells. Total ATPase activities of the plasma membrane fractions from wild-type, DM1, and DM2 yeast cells were 36,42 , and $32 \mathrm{U}$ per $\mathrm{mg}$ of protein, respectively. Gray bars and white bars indicate binding without or with preincubation, respectively, with an excess of $50 \mu \mathrm{M}$ unlabeled Dm-AMP1 for 15 min prior to addition of radiolabeled DmAMP1. Data are averages of triplicate measurements and correspond to one representative experiment out of three. 
plant defensin binding site could serve as an anchor point allowing the plant defensins to insert into or translocate across the plasma membrane, presumably accompanied by the formation of porelike structures permeable to ions or other solutes. The latter hypothesis is supported by our observations that plant defensins including Dm-AMP1 cause a weak but measurable permeabilization of $N$. crassa and $S$. cerevisiae cells to the fluorescent compound SYTOX Green at plant defensin concentrations equivalent to those required for fungal growth inhibition (Thevissen et al., in press). Binding site-mediated insertion in plasma membranes has previously been proposed to explain the antimicrobial activity of a number of antimicrobial proteins (Lakey et al. 1994; Schmitt and Compain, 1995; Chikindas et al. 1993; Van Belkum, 1991; Brotz et al. 1998), but this explanation has so far not gained wide recognition.

Binding sites on $S$. cerevisiae cells for Dm-AMP1 appear to share some characteristics with those of $N$. crassa hyphae. In both cases, binding of $\left[{ }^{35} \mathrm{~S}\right] \mathrm{Dm}-\mathrm{AMP} 1$ was saturable and could be competed for by subfamily A2 plant defensins, but not by subfamily A3 and A4 plant defensins or unrelated proteins. Furthermore, binding of $\left[{ }^{35} \mathrm{~S}\right] \mathrm{Dm}-$ AMP1 was found to be irreversible for both $S$. cerevisiae cells and $N$. crassa hyphae. It is therefore conceivable that a structurally related receptor for subfamily A2 plant defensins might occur in a variety of different fungi. Interestingly, plasma membrane fractions derived from two independently obtained S. cerevisiae mutants, which can grow at DmAMP1 concentrations completely suppressing growth of a wild-type strain, exhibit a substantially decreased binding capacity for $\left[{ }^{35} \mathrm{~S}\right] \mathrm{Dm}-\mathrm{AMP} 1$, compared with plasma membrane fractions derived from wild-type yeast. This finding provides strong support to the idea that binding of DmAMP1 to its binding site on the $S$. cerevisiae plasma membrane is linked to its antifungal effect. The genes affected in the DM1 and DM2 mutants are likely candidates for genes encoding or controlling the Dm-AMP1 receptor site. Genetic evidence has been obtained indicating that the mutations in DM1 and DM2 affect the same nuclear gene (K. Thevissen and W. F. Broekaert, unpublished results). We are currently focusing our efforts on the cloning of this gene in the hope that this will further advance our knowledge of the mode of action of plant defensins.

\section{MATERIALS AND METHODS}

\section{Materials.}

The antifungal peptides Dm-AMP1, Ah-AMP1, Ct-AMP1, and Hs-AFP1 were isolated as described previously by Osborn et al. (1995). Rs-AFP2, Ace-AMP1, Ac-AMP1, MjAMP2, and Ib-AMP4 were isolated as described previously by Terras et al. (1992), Cammue et al. (1995), Broekaert et al. (1992), Cammue et al. (1992), and Tailor et al. (1997), respectively. t-Butoxycarbonyl-L-methionine $N$-hydroxysuccinimidylester (Boc-Met-NHS) was obtained from Bachem (Bubendorf, Switzerland) and Boc- $\left[{ }^{35} \mathrm{~S}\right] \mathrm{Met}-\mathrm{NHS}$ from Amersham International (Slough, UK). Carbonylcyanide mchlorophenylhydrazone (CCCP) and $\beta$-glucuronidase were purchased from Sigma (St. Louis, MO). All other reagents were of reagent grade and were obtained from commercial sources.

\section{Microorganisms.}

Filamentous fungi were grown on six cereal agar and spores were harvested as described by Broekaert et al. (1990). Spore stocks in $20 \%$ ( $\mathrm{vol} / \mathrm{vol})$ glycerol were at a final concentration of $2 \times 10^{7}$ spores per ml. Yeast (Saccharomyces cerevisiae) was grown and stored following standard protocols (Ausubel et al. 1993). The fungal strains used in this study were $\mathrm{Neu}$ rospora crassa FGSC 2489, Botrytis cinerea MUCL 30158, Fusarium culmorum IMI 180420, Alternaria brassicicola MUCL 20297, and Saccharomyces cerevisiae W303-1A (genotype: MATa leu2-3/112 ura3-1 trp1-1 his3-11/15 ade2-1 can1-100 GAL SUC2).

\section{Antifungal activity assay.}

Antifungal activity of protein samples against filamentous fungi was assayed by microspectrophotometry as described previously (Broekaert et al. 1990; Terras et al. 1992). Briefly, in a well of a 96-well microplate, $10 \mu \mathrm{l}$ of the protein sample was mixed with $90 \mu \mathrm{l}$ of potato dextrose broth $(12 \mathrm{~g} / \mathrm{liter}$; Difco, Detroit, MI) containing fungal spores that had been pregerminated for $16 \mathrm{~h}$. Growth was recorded after $48 \mathrm{~h}$ of further incubation at $22^{\circ} \mathrm{C}$. The absorbance at $595 \mathrm{~nm}$ served as a measure for microbial growth (Terras et al. 1992). IC $_{50}$ values (i.e., the concentration of the antifungal protein required to inhibit $50 \%$ of the fungal growth) were calculated from dose-response curves with twofold dilution steps (Terras et al. 1992).

Antifungal activity of protein samples against $S$. cerevisiae was determined in a manner analogous to that for the antifungal activity against filamentous fungi. Briefly, in a well of a 96-well microplate, $15 \mu \mathrm{l}$ of the protein sample was mixed with $138 \mu \mathrm{l}$ of minimal medium $(0.8 \mathrm{~g}$ of CSM per liter, BIO 101, La Jolla, CA; $6.5 \mathrm{~g}$ of yeast nitrogen base without amino acids per liter, Difco; $20 \mathrm{~g}$ of glucose per liter) and $2 \mu \mathrm{l}$ of an overnight culture of yeast cells. The microplates were incubated at $30^{\circ} \mathrm{C}$ without shaking, and the absorbance at $595 \mathrm{~nm}$ was recorded after $20 \mathrm{~h}$ of incubation.

\section{Preparation of microsomal membranes from $S$. cerevisiae cells.}

Microsomal membranes were isolated from $N$. crassa as previously described (Thevissen et al. 1996). Isolation of microsomal membranes from $S$. cerevisiae cells was done in a manner analogous to that for $N$. crassa. Yeast cells were grown overnight in YPD (10 g of yeast extract per liter; $20 \mathrm{~g}$ of peptone per liter, $20 \mathrm{~g}$ of glucose per liter) at $30^{\circ} \mathrm{C}$ and were harvested (absorbance at $600 \mathrm{~nm}=1.10$ ) by centrifugation at $3,500 \times g$ for $10 \mathrm{~min}$. After resuspension of the pellet in homogenization buffer (50 mM Tris, $\mathrm{pH} 7.5 ; 5 \mathrm{mM}$ EDTA; $1 \mathrm{mM}$ EGTA; $0.3 \mathrm{M}$ sucrose, $5 \mathrm{mg}$ of bovine serum albumin per $\mathrm{ml}$ ), the cell suspension was lysed by one passage through a high pressure cell disrupter ( $\mathrm{Z}$ series; Constant Systems, Warwick, UK). The suspension of disrupted cells was subjected to a series of subsequent centrifugation steps: $4,000 \times g$ for $10 \mathrm{~min}$ (with recovery of the supernatant); $15,000 \times g$ for $20 \mathrm{~min}$ (with recovery of the supernatant); $100,000 \times g$ for 60 min (with recovery of the pellet). The final pellet was suspended in $20 \mathrm{ml}$ of wash buffer (1 mM Tris-EGTA; 10\% [vol/ vol] glycerol, $\mathrm{pH} 7$ ) and washed in a glass homogenizer. The suspension was centrifuged at $100,000 \times g$ for $60 \mathrm{~min}$ and the pellet was resuspended in a very small volume of wash buffer 
(approximately $1 \mathrm{ml}$ ). Aliquots were flash frozen in liquid nitrogen and stored at $-80^{\circ} \mathrm{C}$. This fraction contains microsomes that are mainly derived from the plasma membrane and the endoplasmic reticulum. Total protein in the membrane fractions was determined after addition of sodium dodecyl sulfate to a final concentration of $0.5 \%$ (wt/vol), with the bicinchoninic acid assay (Smith et al. 1985) with bovine serum albumin as standard. Total ATPase activity of the membrane fractions was determined as described by Bowman and Bowman (1988) and units are expressed as $\mu \mathrm{mol}$ of phosphate released in $1 \mathrm{~h}$ at $30^{\circ} \mathrm{C}$.

\section{Preparation of ${ }^{35} \mathrm{~S}$-labeled Dm-AMP1.}

Dm-AMP1 was radiolabeled with Boc- $\left[{ }^{35} \mathrm{~S}\right] \mathrm{Met}-\mathrm{NHS}$ at 30 $\mathrm{TBq} / \mathrm{mmol}$ (Amersham International) as described previously for Hs-AFP1 (Thevissen et al. 1997). Specific activities of the labeled Dm-AMP1 preparations were typically around $1 \mathrm{TBq} /$ mmol. Cold-labeled Dm-AMP1 was prepared as described previously for Hs-AFP1 (Thevissen et al. 1997).

\section{Binding assays.}

For binding studies with $N$. crassa hyphae, $N$. crassa was grown at an inoculum density of $3 \times 10^{5}$ spores per $\mathrm{ml}$ as described previously (Thevissen et al. 1996). The medium consisted of half-strength potato dextrose broth (12 g/l; Difco). After $20 \mathrm{~h}$ of incubation at $22^{\circ} \mathrm{C}, 80-\mu \mathrm{l}$ aliquots of the $N$. crassa culture were incubated, unless stated otherwise, with 4 pmol of $\left[{ }^{35} \mathrm{~S}\right] \mathrm{Dm}$-AMP1 (approximately $1.08 \mathrm{TBq} / \mathrm{mmol}$ ) either with or without appropriate concentrations of competing antifungal peptides in a total volume of $100 \mu \mathrm{l}$ in siliconized polypropylene microcentrifuge tubes (Sigma) at $22^{\circ} \mathrm{C}$. Total protein in the $N$. crassa cultures was measured after homogenization by high speed reciprocal shaking in the presence of $10 \%$ (wt/vol) 400 - to $600-\mu \mathrm{m}$ glass beads (Sigma) in a Fastprep apparatus (Bio 101/Savant, Farmingdale, NY). Protein measurement was done by the bicinchoninic acid method (Smith et al. 1985) with bovine serum albumin as standard. Total protein content in $N$. crassa cultures was approximately $1.8 \mathrm{mg}$ protein per ml. After incubation for the time periods indicated, the samples were transferred to wells of a MultiScreen Durapore 96 -well filtration plate $(0.65 \mu \mathrm{m}$ pore size; Millipore, Bedford, MA). After filtration with a MultiScreen vacuum filtration manifold (Millipore), harvested hyphae were washed three times with $100 \mu$ of ice-cold binding buffer (20 $\mathrm{mM}$ MES [morpholineethanesulfonic acid], $50 \mathrm{mM} \mathrm{KCl}, 1$ $\mathrm{mM} \mathrm{MgCl2}, \mathrm{pH}$ 6.2). Filters with the hyphae or microsomal membranes were punched out manually with Multiscreen punch tips (Millipore), suspended in scintillation cocktail (Ready Safe scintillation cocktail; Analis, Gent, Belgium), and counted for ${ }^{35} \mathrm{~S}$ in a liquid scintillation counter. Nonspecific binding was determined as the amount of radioactivity bound in the presence of 25 or $50 \mu \mathrm{M}$ unlabeled Dm-AMP1. Specific binding was calculated by subtracting nonspecific binding from total binding.

For binding studies with $S$. cerevisiae cells, a $S$. cerevisiae culture was grown overnight at $30^{\circ} \mathrm{C}$ (absorbance at $600 \mathrm{~nm}=$ 1.00). The growth medium consisted of half-strength minimal medium $(0.4 \mathrm{~g}$ of CSM per liter, BIO $101 ; 3.25 \mathrm{~g}$ of yeast nitrogen base per liter, Difco; $10 \mathrm{~g}$ of glucose per liter). Binding assays were performed in a manner analogous to that with $N$. crassa.
For binding studies with $S$. cerevisiae microsomal membranes, $2-\mu \mathrm{l}$ aliquots of a membrane suspension containing 1.6 $\mathrm{mg}$ of protein per $\mathrm{ml}$ were incubated with 4 pmol of $\left[{ }^{35} \mathrm{~S}\right] \mathrm{Dm}-$ AMP1 in a total volume of $100 \mu \mathrm{l}$ of binding buffer $(20 \mathrm{mM}$ MES, $50 \mathrm{mM} \mathrm{KCl}, 1 \mathrm{mM} \mathrm{MgCl}_{2}$, pH 6.2) in siliconized polypropylene microcentrifuge tubes at $4^{\circ} \mathrm{C}$.

\section{Reduction of Dm-AMP1.}

Reduction of Dm-AMP1 was performed by the addition of $100 \mathrm{mM}$ Tris- $\mathrm{HCl}(\mathrm{pH} \mathrm{8})$ and $100 \mathrm{mM}$ dithioerythreitol (DTE), followed by incubation at $45^{\circ} \mathrm{C}$ for $1 \mathrm{~h}$. Reagents were removed on a disposable reversed phase $\mathrm{C}_{8}$ silica column (Bond Elut, $500 \mathrm{mg}$ solid phase; Varian, Harbor City, CA). The C8 silica column was subsequently rinsed with $6 \mathrm{ml}$ of distilled water containing $0.1 \%$ ( $\mathrm{vol} / \mathrm{vol})$ trifluoroacetic acid. The reduced peptide was eluted from the latter column with 5 $\mathrm{ml}$ of $50 \%$ ( $\mathrm{vol} / \mathrm{vol}$ ) acetonitrile containing $0.1 \%$ ( $\mathrm{vol} / \mathrm{vol}$ ) trifluoroacetic acid. Protein fractions (monitored by measurement of the absorbance at $280 \mathrm{~nm}$ ) were vacuum dried and redissolved in distilled water.

\section{Isolation of Dm-AMP1-resistant $S$. cerevisiae mutants.}

For the isolation of $S$. cerevisiae mutants resistant to DmAMP1, an overnight culture of wild-type $S$. cerevisiae in minimal medium (0.8 $\mathrm{g}$ of CSM per liter, BIO 101; $6.5 \mathrm{~g}$ of yeast nitrogen base without amino acids per liter, Difco; $20 \mathrm{~g}$ of glucose per liter) was diluted 100 -fold with fresh minimal medium, supplemented with $5 \mu \mathrm{M}$ Dm-AMP1, to a cell density of approximately $10^{6}$ to $2.10^{6}$ cells per ml. This culture was transferred to a $96-$ well microplate in $100-\mu l$ aliquots. After 2 days of incubation at $30^{\circ} \mathrm{C}$, independent Dm-AMP1resistant colonies could be isolated. This selection procedure combines the advantage of selection in liquid medium (stringent selection, minimal amount of Dm-AMP1 needed) with the advantage of selection on solid medium (growth of individual colonies).

\section{ACKNOWLEDGMENTS}

This research was supported in part by the Commission of the European Union (AIR2-CT94-1356) and by a grant from the Belgian National Fund for Scientific Research. K. T. acknowledges receipt of a Postdoctoral Research fellowship from the Onderzoeksfonds of the Katholieke Universiteit of Leuven, Belgium.

\section{LITERATURE CITED}

Ausubel, F. M., Brent, R., Kingston, R. E., Moore, D. D., Seidman, J. G., and Struhl, K. 1993. Pages 13.1.1-13.11.4 in: Current Protocols in Molecular Biology. John Wiley \& Sons, Somerset, NY.

Bowman, E. J., and Bowman, B. J. 1988. Purification of vacuolar membranes, mitochondria and plasma membranes from Neurospora crassa and modes of discriminating among the different H+-ATPases. Methods Enzymol. 157:562-573.

Broekaert, W. F., Cammue, B. P. A., De Bolle, M. F. C., Thevissen, K., De Samblanx, G. W., and Osborn, R. W. 1997. Antimicrobial peptides from plants. Crit. Rev. Plant Sci. 16:297-323.

Broekaert, W. F., Mariën, W., Terras, F. R. G., De Bolle, M. F. C., Proost, P., Van Damme, J., Dillen, L., Claeys, M., Rees, S. B., Vanderleyden, J., and Cammue, B. P. A. 1992. Antimicrobial peptides from Amaranthus caudatus seeds with sequence homology to the cysteine/glycine-rich domain of chitin-binding proteins. Biochemistry 31:4308-4314.

Broekaert, W. F., Terras, F. R. G., Cammue, B. P. A., and Osborn, R. W. 1995. Plant defensins: Novel antimicrobial peptides as components of 
the host defense system. Plant Physiol. (Bethesda) 108:1353-1358.

Broekaert, W. F., Terras, F. R. G., Cammue, B. P. A., and Vanderleyden, J. 1990. An automated quantitative assay for fungal growth. FEMS Microbiol. Lett. 69:55-60.

Brotz, H., Josten, M., Wiedemann, I., Schneider, U., Gotz, F., Bierbaum, G., and Sahl, H. G. 1998. Role of lipid-bound peptidoglycan precursors in the formation of pores by nisin, epidermin and other lantibiotics. Mol. Microbiol. 30:317-327.

Cammue, B. P. A., De Bolle, M. F. C., Terras, F. R. G., Proost, P., Van Damme, J., Rees, S. B., Vanderleyden, J., and Broekaert, W. F. 1992. Isolation and characterization of a novel class of plant antimicrobial peptides from Mirabilis jalapa L. seeds. J. Biol. Chem. 267:22282233.

Cammue, B. P. A., Thevissen, K., Hendriks, M., Eggermont, K., Goderis, I. J., Proost, P., Van Damme, J., Osborn, R. W., Guerbette, F., Kader, J. C., and Broekaert, W. F. 1995. A potent antimicrobial protein from onion seeds showing sequence homology to plant lipid transfer proteins. Plant Physiol. (Bethesda) 109:445-455.

Chikindas, M. L., Garcia, M. J., Driessen, A. J. M., Ledeboer, A. M., Nissen-Meyer, J., Nes, I. F., Abee, T., Konings, W. N., and Venema, G. 1993. Pediocin PA-1, a bacteriocin from Pediococcus acidilactici PAC1.0, forms hydrophilic pores in the cytoplasmic membrane of target cells. Appl. Environ. Microbiol. 59:3577-3584.

Cociancich, S., Ghazi, A., Hétru, C., Hoffmann, J. A., and Letellier, L. 1993. Insect defensin, an inducible antibacterial peptide, forms voltage-dependent channels in Micrococcus luteus. J. Biol. Chem. 268: 19239-19245.

De Samblanx, G. W., Goderis, I. J., Thevissen, K., Raemaekers, R., Fant, F., Borremans, F., Acland, D., Osborn, R. W., Patel, S., and Broekaert, W. F. 1997. Mutational analysis of a plant defensin from radish (Raphanus sativus L.) reveals two adjacent sites important for antifungal activity. J. Biol. Chem. 272:1171-1174.

Harrison, S. J., Marcus, J. P., Goulter, K. C., Green, J. L., Maclean, D. J., and Manners, J. M. 1997. An antimicrobial peptide from the Australian native Hardenbergia violacea provides the first functionally characterised member of a subfamily of plant defensins. Aust. J. Plant Physiol. 24:571-578.

Kagan, B. L., Selsted, M. E., Ganz, T., and Lehrer, R. I. 1990. Antimicrobial defensin peptides form voltage-dependent ion-permeable channels in planar lipid bilayer membranes. Proc. Natl. Acad. Sci. USA 87:210-214.

Kombrink, E., and Somssich, I. E. D. 1995. Defense responses of plants to pathogens. Adv. Bot. Res. 21:1-34.

Lakey, J. H., Van der Goot, F. G., and Pattus, F. 1994. All in the family: The toxic activity of pore-forming colicins. Toxicology 87:85-108.

Landon, C., Sodano, P., Hetru, C., Hoffmann, J., Ptak, M. 1997. Solution structure of drosomycin, the first inducible antifungal protein from insects. Prot. Sci. 6:1878-1884.

Osborn, R. W., De Samblanx, G. W., Thevissen, K., Goderis, I., Torrekens, S., Van Leuven, F., Attenborough, S., Rees, S. B., and Broekaert, W. F. 1995. Isolation and characterisation of plant defensins from seeds of Asteraceae, Fabaceae, Hippocastanaceae and Saxifragaceae. FEBS Lett. 368:257-262.

Schmitt, M. J., and Compain, P. 1995. Killer-toxin-resistant kre12 mutants of Saccharomyces cerevisiae: Genetic and biochemical evidence for a secondary K1 membrane receptor. Arch. Microbiol. 164:435443.

Smith, P. K., Krohn, R. I., Hermanson, G. T., Mallia, A. K., Gartner, F. H., Provenzano, M. D., Fujitomo, E. K., Goeke, N. M., Olson, B. J., and Klenk, D. C. 1985. Measurement of protein using bicinchoninic acid. Anal. Biochem. 150:76-85.

Tailor, R., Acland, D. P., Attenborough, S., Cammue, B. P. A., Evans, I J., Osborn, R. W., Ray, J., Rees, S. B., and Broekaert, W. F. 1997. A novel family of small cysteine-rich antimicrobial peptides from seed of Impatiens balsamina is derived from a single precursor protein. J. Biol. Chem. 272:24480-24487.

Terras, F. R. G., Schoofs, H. M. E., De Bolle, M. F. C., Van Leuven, F., Rees, S. B., Vanderleyden, J., Cammue, B. P. A., and Broekaert, W. F. 1992. Analysis of two novel classes of plant antifungal proteins from radish (Raphanus sativus L.) seeds. J. Biol. Chem. 267: 15301-15309.

Terras, F. R. G., Schoofs, H. M. E., Thevissen, K., Osborn, R. W., Vanderleyden, J., Cammue, B. P. A., and Broekaert, W. F. 1993. Synergistic enhancement of the antifungal activity of wheat and barley thionins by radish and oilseed rape $2 \mathrm{~S}$ albumins and by barley trypsin inhibitors. Plant Physiol. (Bethesda) 103:1311-1319.

Thevissen, K., Ghazi, A., De Samblanx, G. W., Brownlee, C., Osborn, R. W., and Broekaert, W. F. 1996. Fungal membrane responses induced by plant defensins and thionins. J. Biol. Chem. 271:1501815025.

Thevissen, K., Osborn, R. W., Acland, D. P., and Broekaert, W. F. 1997. Specific, high affinity binding sites for an antifungal plant defensin on Neurospora crassa hyphae and microsomal membranes. J. Biol. Chem. 272:32176-32181.

Thevissen, K., Terras, F. R. G., and Broekaert, W. F. Permeabilization of fungal membranes caused by plant defensins leads to fungal growth inhibition. Appl. Environ. Microbiol. (In press.)

Van Belkum, M. J., Kok, J., Venema, G., Holo, H., Nes, I. F., Konings, W. N., and Abee, T. 1991. The bacteriocin lactococcin A specifically increases permeability of lactococcal cytoplasmic membranes in a voltage-independent, protein- mediated manner. J. Bacteriol. 173: 7933-7941. 